\title{
HISTOPATHOLOGICAL PATTERN AND EXPRESSION OF Ki-67, EGFR IN CENTRAL NERVOUS SYSTEM TUMOURS
}

Veena R. Nair', Laila Raji $N^{2}$, Bhavya P. Mohan ${ }^{3}$, Sankar $S^{4}$

1 Junior Resident, Department of Pathology, GMC, Kottayam, Kerala, India.

${ }^{2}$ Professor, Department of Pathology, GMC, Kottayam, Kerala, India.

${ }^{3}$ Assistant Professor, Department of Pathology, GMC, Kottayam, Kerala, India.

${ }^{4}$ Professor and HOD, Department of Pathology, GMC, Kottayam, Kerala, India.

\begin{tabular}{l}
\hline ABSTRACT \\
BACKGROUND \\
Central Nervous system (CNS) tumours constitute only about 1-2\% of all neoplasms, but they show a varied histopathological \\
spectrum. A WHO grading scheme is followed in the reporting of these tumours which play a key role in deciding the choice of \\
therapies. Immunohistochemical markers like Ki-67 and EGFR are found to have a significant role in predicting the behaviour of \\
these tumours. Hence in tumours where proper grading becomes difficult, the usage of these markers will be extremely helpful. In \\
this study, the histopathological pattern, grading and expression of Ki-67 and EGFR in CNS tumours, received during the study \\
period of 18 months, are described. Thereafter the relationship between the expression of these markers and the WHO grades is \\
also evaluated.
\end{tabular}

\section{MATERIALS AND METHODS}

A descriptive study was conducted to describe the histopathological pattern and the expression of Ki-67 and EGFR in CNS tumours received in the Department of Pathology, Government Medical College, Kottayam for a period of 18 months (June 2017 -November 2018). The relationship between the expression of these markers and the histological grades was also evaluated. Statistical analysis was done with available software.

\section{RESULTS}

Among the 80 cases of CNS tumours studied, 48 cases (60\%) were Meningiomas. Most of the cases had a Ki 67 value between 0-5 \% (50 cases, 62.5\%). It was found that in all types of CNS tumours studied, Ki-67 increased with increase in WHO grade. Among the glioma cases studied, 70.8\% of them had an EGFR score of 3+ and among meningiomas, $62.5 \%$ had an EGFR Immunoreactive score (IRS) between 11 and 15. By statistical analysis, it was found that both WHO grade and EGFR expression in these tumours are associated. But in case of gliomas, increase in WHO grade improves our prediction for EGFR to be high $(3+)$ and among meningiomas, increase in WHO grade improves our prediction for EGFR to be low (0-5). In case of remaining CNS tumours, majority of them showed EGFR negativity.

\section{CONCLUSION}

In our study, Meningiomas were the most common histological type. Ki-67 values in all types of CNS tumours increased with increase in WHO grades. All gliomas and meningiomas showed expression of EGFR. A significant association exists between WHO grades and EGFR expression of these tumours.

\section{KEY WORDS}

Histopathological Pattern; CNS Tumours; Ki67; EGFR.

HOW TO CITE THIS ARTICLE: Nair VR, Raji LN, Mohan BP, et al. Histopathological pattern and expression of KI-67, EGFR in central nervous system tumours. J. Evolution Med. Dent. Sci. 2019;8(09):580-585, DOI: 10.14260/jemds/2019/129

\section{BACKGROUND}

Central Nervous system is responsible for the co-ordinated functioning of different organ systems in our body. As compared to other organ systems, central nervous system only contributes to $1-2 \%$ of all neoplasms. Even though the proportion is too small, the histopathological patterns and pathogenesis show extreme diversity.

'Financial or Other Competing Interest': None.

Submission 21-12-2018, Peer Review 11-02-2019,

Acceptance 19-02-2019, Published 04-03-2019.

Corresponding Author:

Dr. Veena R. Nair,

Junior Resident,

Department of Pathology,

GMC, Gandhinagar, P. O,

Kottayam-686008,

Kerala, India.

E-mail: veenarnair1989@gmail.com

DOI: $10.14260 /$ jemds $/ 2019 / 129$

(c) (i) $(9)$
CNS tumours have a histological grading scheme as per WHO guidelines. This provides a means of predicting the biological behaviour of a neoplasm and influence the choice of therapies Assessment of the histological pattern helps policy making for tumour screening and early treatment.

There are a large number of immunohistochemical markers in use for CNS tumours. These serve as both diagnostic and prognostic tools. One group among these markers include those which determines the proliferative activity. Ki-67 and Epidermal Growth Factor Receptor (EGFR) are two such markers.

Ki-67 protein expression is strictly associated with cell proliferation. The antigen can be detected within the nucleus during interphase. It is present during all active phases of the cell cycle $(\mathrm{G}(1), \mathrm{S}, \mathrm{G}(2)$, and mitosis), but it is absent in resting cells (G-0). Hence it makes an excellent marker for determining proliferative activity of a neoplastic population. It has been widely documented for various human tumours, 
including CNS tumours and is very helpful in predicting the biological behaviour of the tumours.

Epidermal growth factor receptor is expressed in a large number of tumours which include meningiomas, gliomas, cancers of the lung, colon, breast and ovary. It acts through its cognate receptor resulting in cell proliferation and evasion from apoptosis. Targeting of EGFR has been proposed as a possible therapeutic strategy in case of many CNS tumours especially gliomas.

Several studies have shown conflicting results regarding the histopathological pattern of CNS tumours and role of Ki67 labelling index and EGFR in predicting their biological behaviour. Hence this study is to be conducted to investigate the histopathological pattern and expression of Ki-67 and EGFR in CNS tumours.

\section{MATERIALS AND METHODS \\ Type of Study}

Descriptive study.

\section{Study Period}

18 months (June 2017-November 2018).

\section{Study Setting}

Department of Pathology, Government Medical College, Kottayam.

\section{Sample Size}

Sample size $N=(4 p q) / d^{2}$

$\mathrm{p}=$ prevalence $/$ proportion in previous study

$\mathrm{q}=100-\mathrm{p}$

$\mathrm{d}=$ precision/allowable error.

The primary objective of this study is to describe the histopathological pattern of CNS tumours received in the department of Pathology, Government Medical College, Kottayam during a period of 18 months. Hence the sample size is calculated based on a similar study done by Chawla. $\mathrm{N}$ et al. ${ }^{1}$

Proportion of astrocytomas in previous study $=55.8 \%{ }^{1}$.

So, $\mathrm{p}=55.8, \mathrm{q}=100-55.8=44.2, \mathrm{~d}=20 \%$ of $\mathrm{p}=11.2$

Sample size, $N=(4 p q) / d^{2}=(4 \times 55.8 \times 44.2) /(11.2)^{2}=78.7$

Taking sample size as 80

\section{Inclusion Criteria}

First 80 histologically diagnosed cases of Central Nervous System tumours were included.

\section{Exclusion Criteria}

Cases without proper data, inadequate specimen, tumours of peripheral nervous system were excluded.

\section{Study Procedure}

Clinical details of each case were recorded first, followed by gross examination of the specimen. All specimens were fixed in formalin and embedded in paraffin. 4 microns thick sections were stained with $\mathrm{H} \& \mathrm{E}$ for routine histological examination. Once the diagnosis and grading were done with $\mathrm{H} \& \mathrm{E}$ stained sections, immunohistochemical staining were performed using mouse monoclonal antibody for Ki-67 and rabbit monoclonal antibody for EGFR.

\section{Immunohistochemical Evaluation of Ki-67 in CNS Tumours}

The sections stained with immunohistochemical markers were first scanned using a $40 \times$ objective. An eye grid was used for the areas with the highest density of labelled tumour cells (hot spots). At least 1000 tumour cells were examined. All the immunoreactive tumour cell nuclei were counted. The Ki-67 proliferation index was defined as the percentage of immunoreactive tumour cell nuclei among the total number of cells.

\section{Immunohistochemical Evaluation of EGFR in Gliomas}

The presence of EGFR is determined using the percentage of immuno-stained cells per 200 cells in 5 fields. Both membrane and cytoplasmic positivity were taken into consideration. The EGFR scoring system is based on the number of positive cells. It is as follows: negative $(-)$, no positive cells observed in the random fields; weak positive $(+),<25 \%$ positive cells; moderately positive $(++), 25-50 \%$ positive cells; and strongly positive $(+++),>50 \%$ positive cells.

\section{Immunohistochemical Evaluation of EGFR in Meningiomas}

Both intensity score and percentage score were assessed. Staining intensity (intensity score) was scored on a scale of 0 to 3 . " 0 " stands for absent staining, " 1 " for weak staining, " 2 " for moderate staining and " 3 " for strong staining of the tumor specimen. The percentages of immunoreactive cells (Percentage score) was scored from 1 to $5.1(<20 \%$ of the sample exhibiting staining); $2(21-40 \%$ of the sample exhibiting staining); 3 (41-60\% of the sample exhibiting staining); 4 (61-80\% of the sample exhibiting staining), and 5 (81-100\% of the specimen stained). From these values, an immunoreactive score (IRS) was calculated by multiplying the percentage score and intensity score.

\section{Data Management and Analysis}

The data was entered in Microsoft excel and further statistical analysis was done using SPSS software (version 25). The statistical methods used were:

1. Mean, frequency, standard deviation and proportion for:

- Age distribution

2. Frequency and proportion for:

- Gender distribution.

- Location of CNS tumours.

- Histological types and subtypes.

- WHO grades, ki-67 \& EGFR in CNS tumours.

3. Chi-square test to find out

- Association between WHO grades and expression of EGFR in gliomas and meningiomas.

4. Somers' D, Kendall's tau-b and Gamma measures to evaluate the degree and direction of association.

\section{RESULTS}

The mean age of the study group was $52.25 \pm 13.67$ years with female to male ratio of 1.1:1.

The majority of the tumours were located in the frontal region (25 cases, $31.3 \%$ ) followed by spinal cord (12 cases, $15 \%$ ) and temporal region (9 cases, $11.3 \%$ ).

The most frequent histological type was found to be Meningiomas (48 cases, $60 \%$ ), followed by Astrocytomas (20 
cases, $25 \%$ ). Transitional meningioma (20 cases, $41.7 \%$ ) was the most frequent subtype among meningiomas and Glioblastoma ( 12 cases, $50 \%$ ) was the most frequent subtype among gliomas.

Most of the tumours were of grade I (50 cases, $62.5 \%$ ) followed by grade II and grade IV (12 cases, 15\% each). Among the 24 cases of gliomas studied, most of them $(12$ cases, 50\%) belonged to Grade IV category. Among the 48 cases of meningioma studied, majority of them were of grade I category ( 42 cases, $87.5 \%$ ).

Most of the cases had a Ki-67 value between 0-5\% (50 cases, $62.5 \%$ ). Majority of the grade I tumours (94\%) had their ki-67 values between $0-5 \%$, while grade II tumours (50\%) had their ki-67 values between 6-10\%. In case of grade III tumours, majority (83\%) had ki-67 values more than $15 \%$ and majority of grade IV tumours (83\%) had their ki-67 values more than $20 \%$.

Among the 24 glioma cases studied, the single grade I case had EGFR expression of $2+$ score. In case of Grade II tumours, $50 \%$ of them had a score of $2+$ and remaining $50 \%$ had a score of $3+.60 \%$ of the grade III tumours had a score of $3+$. Majority of the grade IV cases $(91.7 \%)$ had a score of $3+$.

Majority of the Grade I meningioma cases (69\%) had an IRS between 11-15. In case of Grade II meningioma cases, $60 \%$ had their IRS less than 10 . Only one case of Grade III meningioma was studied with an IRS of 5 .

The association between WHO grades and EGFR expression in case of gliomas and meningiomas were checked separately using a Chi-square test.

\begin{tabular}{|c|c|c|c|c|}
\hline & \multicolumn{2}{|c|}{ Gliomas } & \multicolumn{2}{c|}{ Meningiomas } \\
\hline & Value & $\mathrm{p}$ Value & Value & $\mathrm{p}$ Value \\
\hline Pearson Chi-Square & 16.894 & .010 & 28.594 & .000 \\
\hline Likelihood Ratio & 15.418 & .017 & 17.209 & .002 \\
\hline No. of Valid Cases & 24 & & 48 & \\
\hline
\end{tabular}

In both instances, $\mathrm{p}$ value was found to be $<0.05$, which means there is association between these tumours and their respective WHO grades. The degree and direction of association were assessed by using Somers' D, Kendall's tau-b and Gamma measures.

\begin{tabular}{|c|c|c|c|c|c|}
\hline & \multicolumn{2}{|c|}{ Gliomas } & \multicolumn{2}{|c|}{ Meningiomas } \\
\hline & & Value & p Value & Value & p Value \\
\hline \multirow{2}{*}{ Somers' D } & $\begin{array}{l}\text { WHO Grade } \\
\text { Dependent }\end{array}$ & .488 & .005 & -.297 & .022 \\
\hline & $\begin{array}{c}\text { EGFR } \\
\text { Dependent }\end{array}$ & .341 & .005 & -.677 & .022 \\
\hline \multicolumn{2}{|c|}{ Kendall's tau-b } & .408 & .005 & -.449 & .022 \\
\hline \multicolumn{2}{|c|}{ Kendall's tau-c } & .328 & .005 & -.227 & .022 \\
\hline \multicolumn{2}{|c|}{ Gamma } & .612 & .005 & -.870 & .022 \\
\hline
\end{tabular}

Here a positive association was noted with $\mathrm{p}$ value 0.005 in case of gliomas and a negative association was noted in case of meningiomas with $\mathrm{p}$ value 0.022 . This means the association is significant and it is helpful in predicting the grade of the tumours from the EGFR expression.

\section{H \& E Sections of Different CNS Tumours}
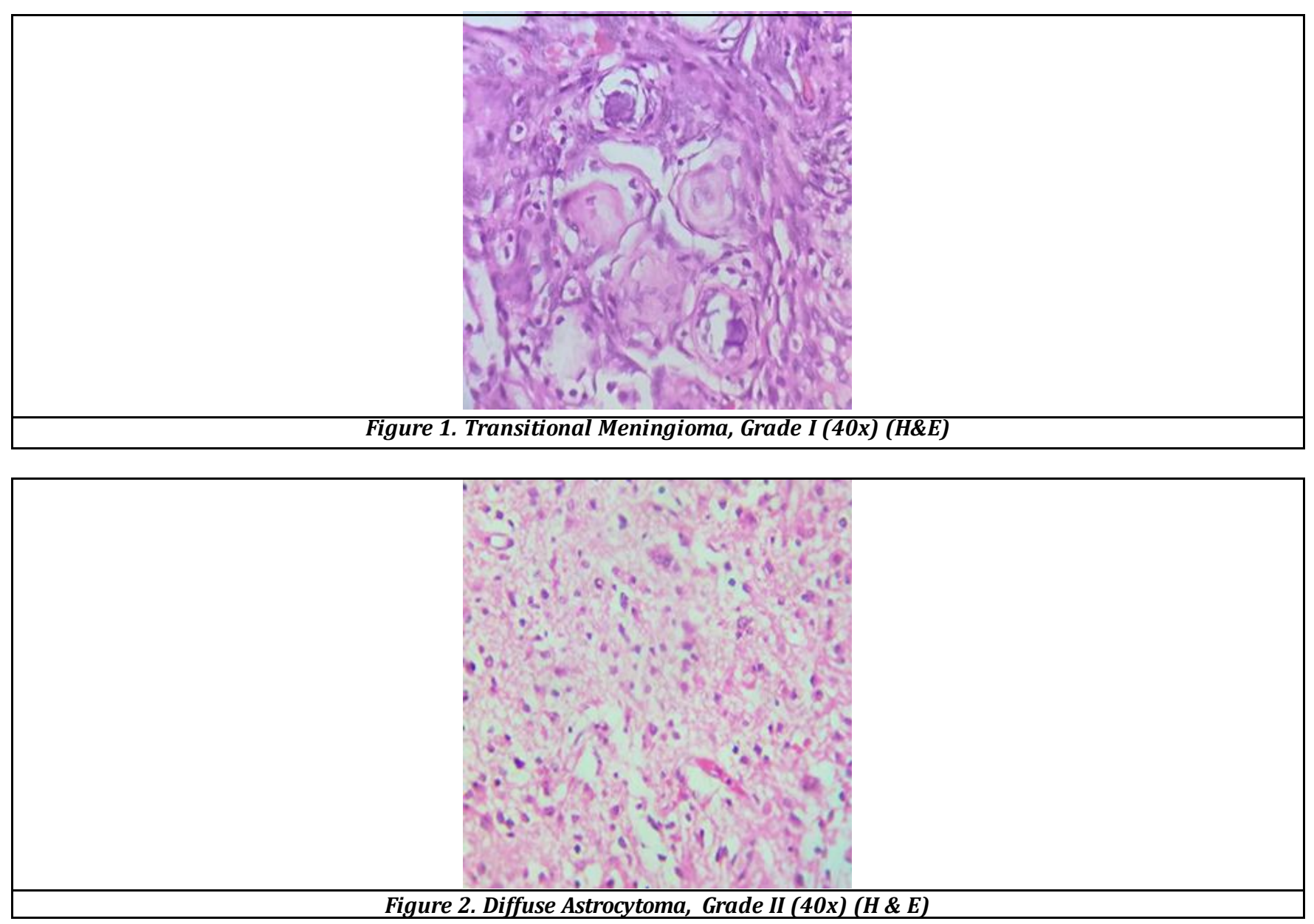
Immunohistochemical Staining Among different Grades of CNS Tumours

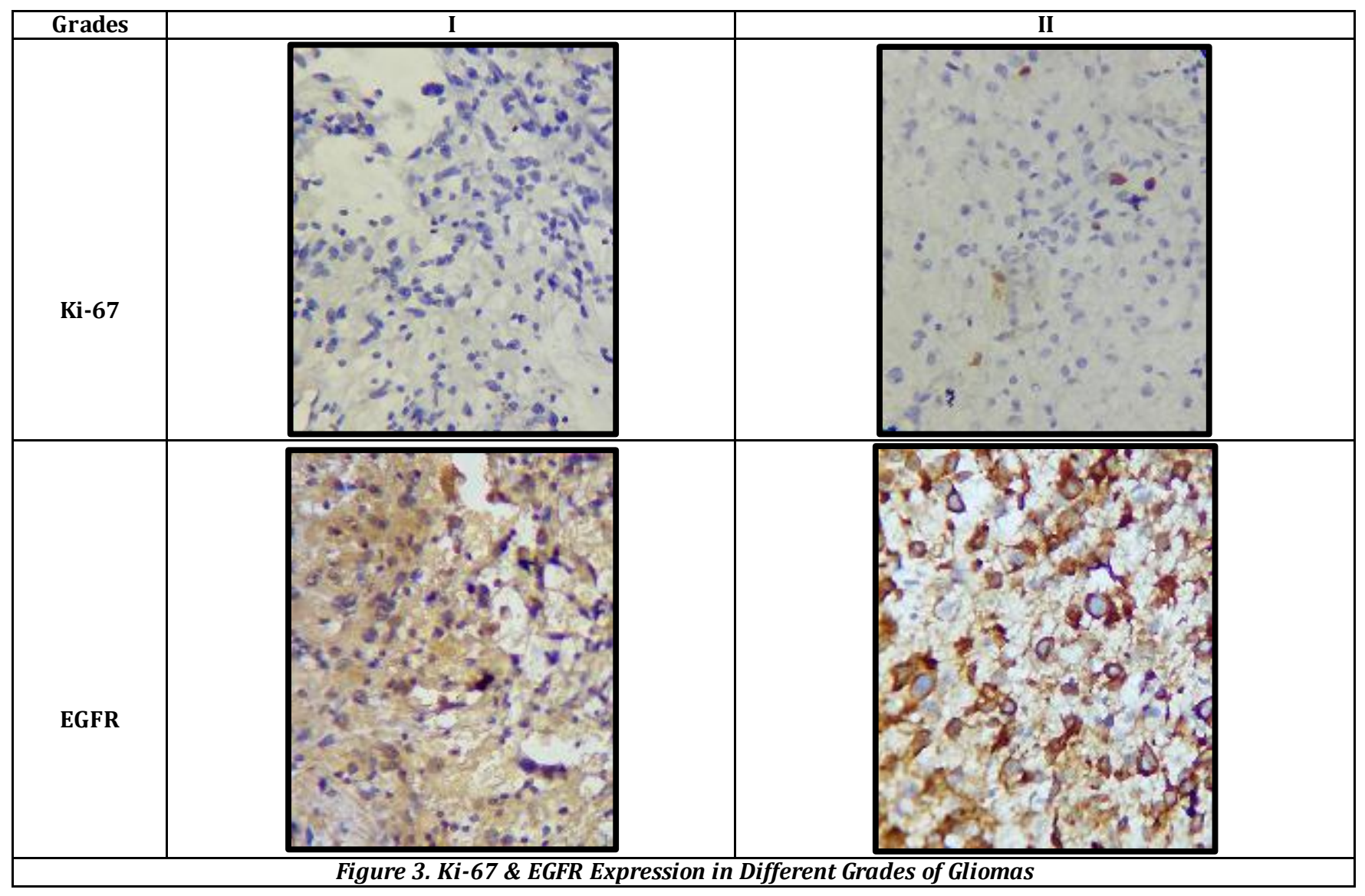

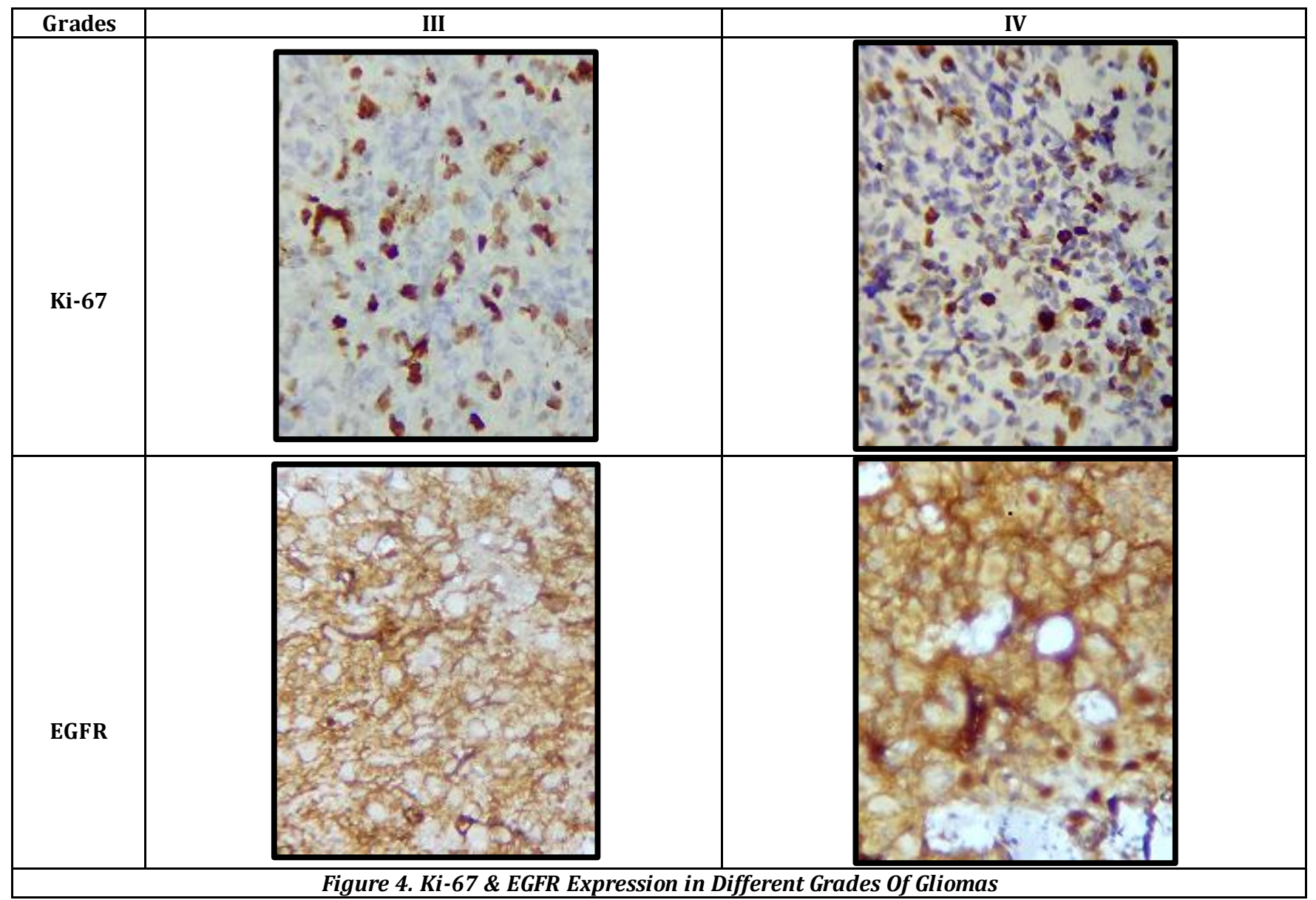




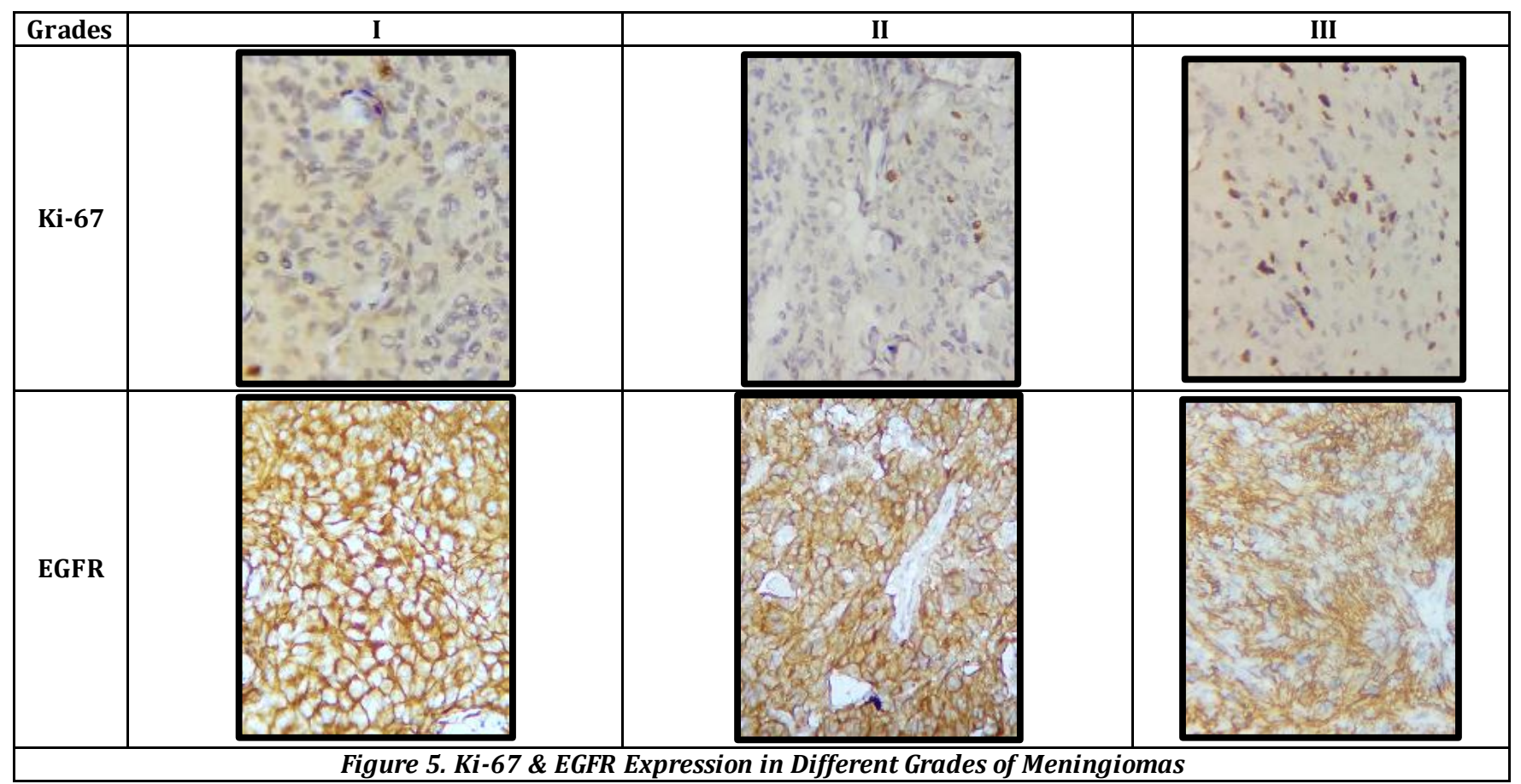

\section{DISCUSSION}

The present study was conducted on 80 cases of Central Nervous System tumours received in the Department of Pathology, Govt. Medical College, Kottayam between June 2017 and November 2018.

The mean age of the study population was $52.25 \pm 13.67$ years which was comparable with a study conducted by Majjid N et $\mathrm{al}^{2}$ in 2013 which was $45 \pm 5$ years.

The Female: Male ratio in the present study was 1.1:1 which was comparable to a study by Sumathi $V$ et $\mathrm{al}^{3}$ in which the female to male ratio was 1.2:1.

The specific location of each tumour was noted, and it was found that most of the tumours were located in the frontal region (25 cases, 31.3\%) followed by spinal cord (12 cases, $15 \%$ ) and temporal region (9 cases, $11.3 \%$ ). This was comparable with a study conducted by Masoodi $\mathrm{T}$ et $\mathrm{al}^{4}$ in which frontal lobe $(20.7 \%)$ was the commonest intracranial location of tumours.

Among the 80 cases studied, Meningiomas (48 cases, $60 \%$ ) was the predominant histological type followed by Astrocytomas (20 cases, 25\%). This was comparable with a study conducted by Nagnath Kanthikar S et $\mathrm{al}^{5}$ in which meningeal tumours formed the predominant category (40\%). Another study done by Ghanghoria S et $\mathrm{al}^{6}$ also had similar observation with meningeal tumours forming the predominant category (41.5\%).

\begin{tabular}{|c|c|c|c|}
\hline Study & $\begin{array}{c}\text { Year of } \\
\text { Study }\end{array}$ & $\begin{array}{c}\text { No. of } \\
\text { Cases }\end{array}$ & $\begin{array}{c}\text { Commonest } \\
\text { Histological Type }\end{array}$ \\
\hline $\begin{array}{c}\text { Nagnath } \\
\text { Kanthikar S et al }^{5}\end{array}$ & 2017 & 38 & Meningiomas (40\%) \\
\hline Ghangh oria S et al $^{6}$ & 2014 & 65 & Meningiomas (41.5\%) \\
\hline Present Study & 2018 & 80 & Meningiomas (60\%) \\
\hline Table 1. Comparison of Histological Type of Study Group \\
with Other Studies \\
\hline
\end{tabular}

In the study population, each tumour was categorised into different histological subtypes. Among astrocytic tumours, Glioblastomas (12 cases, 15\%) formed the predominant category. This was comparable to a study done by Gupta D et al, ${ }^{7}$ where Glioblastoma $(13.5 \%)$ formed the predominant category. Similar observation was made by Ahsan J et $\mathrm{al}^{8}$ where Glioblastomas (22.6\%) formed the most frequent astrocytic tumour.

\begin{tabular}{|c|c|c|c|}
\hline Study & $\begin{array}{c}\text { Year of } \\
\text { Study }\end{array}$ & $\begin{array}{c}\text { No. of } \\
\text { Cases }\end{array}$ & $\begin{array}{c}\text { Commonest Astrocytic } \\
\text { Sub Type }\end{array}$ \\
\hline${\text { Gupta D et } \mathrm{al}^{7}}^{2}$ & 2017 & 59 & Glioblastomas $(13.5 \%)$ \\
\hline${\text { Ahsan J et } \mathrm{al}^{8}}^{2}$ & 2015 & 761 & Glioblastomas $(22.6 \%)$ \\
\hline Present Study & 2018 & 80 & Glioblastomas $(15 \%)$ \\
\hline \multicolumn{2}{|c|}{ Table 2. Comparison of Histological Subtype of } \\
Astrocytomas of Study Group with Other Studies \\
\hline
\end{tabular}

Among the meningeal tumours, Transitional meningioma (20 cases, 25\%) was the predominant one. This was comparable to a study done by Babu S et al. ${ }^{9}$

Tumours in our study population were graded according to WHO 2016 guidelines. Among the 80 cases studied, most of the tumours are of grade I (50 cases, $62.5 \%$ ). This was comparable with a study done by Gupta $\mathrm{D}$ et $\mathrm{al}^{7}$ in which $47.4 \%$ were of Grade I. Another study by Sumathi $\mathrm{V}$ et $\mathrm{al}^{3}$ also had similar observation.

\begin{tabular}{|c|c|c|c|}
\hline Study & $\begin{array}{c}\text { Year of } \\
\text { Study }\end{array}$ & $\begin{array}{c}\text { No. of } \\
\text { Cases }\end{array}$ & $\begin{array}{c}\text { Commonest } \\
\text { Grade }\end{array}$ \\
\hline Gupta D et al ${ }^{7}$ & 2017 & 59 & Grade I (47.4\%) \\
\hline Sumathi V et al & 2016 & 83 & Grade I $(37.2 \%)$ \\
\hline Present Study & 2018 & 80 & Grade I $(62.5 \%)$ \\
\hline Table 3. Comparison of Commonest Grade Of CNS Tumours \\
of Study Group with Other Studies
\end{tabular}

Most of the cases had their ki-67 value between 0-5\% (50 cases, $62.5 \%$ ). It was found that higher grades of tumours had higher values of ki-67. EGFR showed varied expression in gliomas and meningiomas. In most of the cases studied, EGFR positivity was membranous. It is comparable to a study done by Hatanpaa $\mathrm{K}$ et al. ${ }^{10} \mathrm{~A}$ difference in positivity was noted in Grade I glioma where the positivity was predominantly 
cytoplasmic. But none of the studies referred had observed such a difference in EGFR expression. It is noted that there is an increase in expression of EGFR as we go from lower to higher grades of gliomas. But in case of meningiomas, an inverse relation is noted. ie, the score of EGFR decreased as we go from lower to higher grades of meningioma.

By statistical analysis, it was found that there is significant association between EGFR expression and WHO grades in case of both gliomas and meningiomas. The relation is positive in case of gliomas and negative in case of meningiomas. Hence if we get a higher EGFR expression for gliomas, it can be predicted that the corresponding WHO grade will be higher and the reverse for meningiomas. This is comparable to studies done by Xinhua Hu et al ${ }^{11} \&$ Dalia. A. Elsers $^{12}$ respectively.

\section{CONCLUSION}

The most common CNS tumour in this study is Meningioma followed by Astrocytoma. Both Ki-67 and EGFR expression in CNS tumours are related to WHO grades. Ki-67 increased with increasing grades. EGFR in gliomas showed positive correlation with WHO grades, whereas in Meningiomas, they showed negative correlation.

\section{ACKNOWLEDGEMENTS}

I express my heartfelt thanks \& gratitude to Dr. Sankar S, Head of the Department, and my guide Dr. Laila Raji. N, Professor, Department of Pathology, Government Medical College, Kottayam for their passion, dedication and help.

\section{REFERENCES}

[1] Chawla N, Kataria SP, Malik S, et al. Histopathological spectrum of central nervous system tumours in a tertiary care referral centre - a one year study. International Journal of Basic and Applied Medical Sciences 2014;4(2):141-5.

[2] Majid H, Ali Z, Md Rahman R, et al. Histological subtypes of brain tumor: pattern in a hospital in Dhaka, Bangladesh. Chattagram Maa-O-Shishu Hospital Medical College Journal 2013;12(1):9-11.
[3] Velayutham, Balakrishnan, Krishna SS, et al. Histopathological spectrum and grading of CNS tumours in tertiary centre: case study of 83 cases. Journal of Evidence Based Medicine and Healthcare 2016;3(45):2240-3.

[4] Masoodi T, Gupta RK, Singh JP, et al. Pattern of central nervous system neoplasms: a study of 106 cases. JK Practitioner 2012;17(4):42-6.

[5] Kanthikar SN, Nikumbh DB, Dravid NV. Histopathological overview of central nervous system tumours in North Maharashtra, India: a single center study. Indian Journal of Pathology and Oncology 2017;4(1):80-4.

[6] Ghanghoria S, Mehar R, Kulkarni C, et al. Retrospective histological analysis of CNS tumors - a 5 year study. International Journal of Medical Science and Public Health 2014;3(10):1205-7.

[7] Gupta D, Kotwal S, Suri J. Study of histopathological pattern of central nervous system tumours in a tertiary care hospital - a 3 year retrospective study. International Journal of Scientific Research 2017;6(6):61-3.

[8] Ahsan J, Hashmi SN, Muhammad I, et al. Spectrum of central nervous system tumours-a single center histopathological review of 761 cases over 5 years. J Ayub Med Coll Abbottabad 2015;27(1):81-4.

[9] Babu S, Uppin SG, Uppin MS, et al. Meningiomas: correlation of Ki67 with histological grade. Neurology India 2011;59(2):204-7.

[10] Hatanpaa KJ, Burma S, Zhao D, et al. Epidermal growth factor receptor in glioma: signal transduction, neuropathology, imaging and radioresistance. Neoplasia 2010;12(9):675-84.

[11] $\mathrm{Hu}$ X, Miao W, Zou Y, et al. Expression of p53, epidermal growth factor receptor, $\mathrm{Ki}-67$, and $0^{6}$. methyguanine - DNA methyltransferase in human gliomas. Oncology Letters 2013;6(1):130-4.

[12] Elsers DA, Aboulhagag NA. Expression of Ki-67, EGFR and its ligand in different grades of Meningiomas. AAMJ 2012;10(3):34-56. 